\title{
VENCENDO A COMPLEXIDADE: UM CONCEITO DE FITNESS ORGANIZACIONAL
}

Markus Schwaninger

Professor de Management do Instituto de Administração de Empresas da Universidade

de St. Gallen, Suiça.

RESUMO: Os enfoques da administração de empresas baseados em uma perspectiva meramente econômica carecem de um fundamento teórico capaz de sustentar um management dirigido à viabilidade e ao desenvolvimento organizacional. O autor propõe um quadro analítico novo para o design e o (auto)controle de empresas, baseado na cibernética organizacional e voltado para um fitness organizacional abrangente. Esse quadro focaliza um management de complexidade, que implica uma (auto)pilotagem integral, recorrendo às noções de pré-controle e de viabilidade além da sobrevivência. A argumentação é corroborada mediante evidência empírica.

ABSTRACT: The approaches to the strategic management of organizations, which are based on an exclusively economic perspective, lack an underlying theory capable of enhancing organizational viability and development. The author proposes a new framework to support the design and control of organizations based on organizational cybernetics and directed towards full-fledged organizational fitness. This framework focuses on the management of complexity, leading to integral (self-)control and including the notions of "pre-control" and "viability beyond survival". The argument of the paper is corroborated by empirical evidence.

PALAVRAS-CHAVE: fitness organizacional, management de complexidade, controle integral, Modelo do Sistema Viável, design organizacional, viabilidade além da sobrevivência, pré-controle.

KEY WORDS: organizational fitness, complexity management, integral control, Viable System Model, organization design, viability beyond survival, pre-control. 
O desafio mais exigente com que as empresas estão se defrontando é a complexidade proliferadora e quase onipresente. Na medida em que o meio ambiente se torna mais complexo, a inteligência organizacional no sentido de previsão, adaptabilidade e aprendizagem torna-se cada vez mais crítica para um sistema social sobreviver e desenvolver-se.

Os modelos de controle organizacional em uso são insuficientes para confrontar essa crescente complexidade. A ciência da cibernética fornece modelos eficazes para vencer esse desafio-chave. $O$ texto a seguir visa a oferecer uma concepção abrangente do fitness organizacional. Para desenvolver essa teoria, será sintetizado o recente progresso nos campos da teoria de planejamento e da cibernética.

\section{As limitações dos conceitos tradicionais}

"O que torna uma organização eficiente?", "qual é a base da eficácia de uma organização?" e, particularmente, "como pode uma organização tornar-se mais inteligente?" Essas são questões recorrentes que preocupam tanto os administradores quanto os teóricos da administração. Dependendo dos modelos adotados, as respostas têm sido diversas, freqüentemente controversas ou de valor duvidoso.

O papel da eficiência tem sido superestimado, levando ao menosprezo dos níveis superiores de efetividade. Ou, mais precisamente, o pensamento a curto prazo tem freqüentemente suprimido uma orientação de longo prazo. Apesar do volume crescente de literatura sobre estratégia empresarial, um grupo de pesquisadores do MIT (Massachusetts Institute of Technology) observou que a indústria norte-americana tem sido "prejudicada por reduzidos horizontes de planejamento e uma crescente preocupação com o lucro a curto prazo". ${ }^{1}$ Esses autores questionam por que as empresas americanas são menos dispostas que suas rivais a passar por períodos de altos investimentos e lucros reduzidos para alcançar "competências-chave". Isso faz lembrar o lamento proferido por John Ruskin há mais de cem anos: "We pour our whole (masculine) energy into the false business of money-making". ${ }^{2}$

Esse não é um discurso para se negar a importância do lucro em si. A longo prazo, nenhum negócio é capaz de sobreviver se não for lucrativo. Os lucros são um pré-requisito para manter o investimento e a essência de uma companhia. Nas palavras precisas de Peter Drucker, o lucro é "the cost of staying in business". ${ }^{3}$

Mesmo sendo o lucro um pressuposto necessário para a sobrevivência, uma mentalidade voltada para o lucro não é suficiente para garantir a viabilidade de uma companhia. Pelo contrário, o objetivo frequientemente citado da "maximização dos lucros" torna-se, a longo prazo, mais um obstáculo do que um orientador para um desempenho superior.

Em um contexto de mudanças rápidas, o nível de lucros, bem como a cotação na bolsa, não constitui medida adequada da efetividade organizacional. Dadas as imperfeições dos mercados de capitais e de informações, aqueles são, em princípio, não mais que indicadores do sucesso a curto prazo.

Recorrendo a uma analogia: avaliar a eficácia de um negócio pelo nível do lucro que ele proporciona é como medir a temperatura para tirar conclusões sobre a estação do ano em que se está. Para esse fim, o calendário, e certamente não o termômetro, seria a fonte apropriada de informação. Da mesma forma como a temperatura referente ao clima, o lucro no mundo dos negócios é um orientador inerente de curto prazo. Em contrapartida, o comportamento de uma empresa a longo prazo é movido por fatores e relacionamentos causais diferentes. Para lidar com isso adequadamente, uma lógica distinta e uma outra língua são necessárias.

A lucratividade como indicador está longe de ser obsoleta para um administrador: desde que Fra Luca Pacioli introduziu a contabilidade dupla em 1494, a maioria das empresas usa e continua usando esse valioso instrumento de um modo mais ou menos inalterado para lidar com receitas, custos e lucros daí resultantes. Porém, apesar de sua utilidade fundamental, a contabilidade é suscetível de enganar os administradores, caso seja usada para proporcionar lições para as quais não é destinada. A conta de resultados é um modelo apropriado para refletir a situação econômica de um negócio em nível operativo. Porém, possíveis sinais tirados (da conta dos resultados) para orientar a estratégia muito provavelmente apontarão exatamente a direção errada. À luz da recente teoria de planejamento, ${ }^{4}$ seria um erro con-
1. BERGER, $S$. et al. Towards a new industrial America. Scientific American. v.260, p.21-9, June 1989

2. RUSKIN, J. First published 1865 Sesame and Lilies. London: George Allen 1907.

3. DRUCKER, P. F. Managing in turbulent times. London: Heinemann, 1980.

4. GÄLWEILER, A. Strategische Unternehmensführung, zusammengestellt, bearbeitet and ergänzt von Markus Schwaninger. 2.ed. Frankturt/New York: Campus, 1990. 
5. ESPEJO $R$ SCHUHMANN, W. SCHWANINGER, M., BILELLO, U. Organizational Transformation ano Learning. A Cybernetic Approach to Management. Chichester: Wiloy, 1996: SCHWANINGER, M. Integrale Unternehmensplanung, Frankfurt/New York: Campus, 1989.

6. CAMERON, K. S., WHETTEN, D. A. (eds.) Organizational effectiveness. a comparison of multiple models. New York Academic Press, 1983; LEWIN, A. Y. MINTON, J. W. Determining organizationa effectiveness: another look and an agenda for research. Management Science, v.32. p.514-38, 1986; ZAMMUTO, R. F Assessing organizational effectiveness. Albany, N.Y.: State University of New York Press, 1982

7. ULRICH, H. Management. Bern/ Stuttgart: Haupt, 1984.

8. BEER, S. 1979. The heart of enterprise. Chichester: Wiley, 1979; _ Braln of the firm. 2.ed. Chichester: Wlley, 1981; Diagnosing the system for organisations. Chichester: Wiley, 1985; ESPEJO, R.; HARNDEN, R. (eds.) The viable system model. interpretatlons and applications of Stafford Beer's VSM. Chichester: Wiley, 1989. siderar o lucro uma meta estratégica, como fica implícito em grande parte da literatura sobre administração de empresas. ${ }^{5}$ Apesar disso, muitas empresas ainda estão sendo dirigidas principalmente com base nas variáveis tradicionais da contabilidade.

Em tempos de estabilidade econômica e em períodos de crescimento contínuo, as fraquezas de tal enfoque de controle não vêm à tona. Mas, em um contexto de instabilidade e transformação dinâmica, as empresas geridas sob a orientação voltada única - ou principalmente - ao lucro tornam-se facilmente vítimas de sua própria miopia. Isso foi demonstrado pelo aumento do número de falências como consequiência das crescentes turbulências na economia mundial durante os anos 80 e 90 .

À medida que a dificuldade de se garantir a viabilidade de uma companhia aumenta, os conceitos tradicionais de controle se tornam cada vez mais obsoletos. Não há dúvida que os teóricos da administração têm dedicado um esforço substancial para tratar da eficácia organizacional sob uma perspectiva mais ampla. Porém, por enquanto, o estado das coisas ainda é considerado imaturo, incoerente e, portanto, insatisfatório pelos peritos do campo. ${ }^{6}$

Para concluir, um novo conceito baseado em uma visão mais abrangente do fitness organizacional se faz necessário. Duas áreas do progresso científico parecem ser de particular relevância para atender a essa necessidade: a cibernética e a teoria de planejamento. $\mathrm{O}$ objetivo do texto a seguir é pôr em relevo um novo enfoque de fitness organizacional surgido de uma síntese de conceitos dessas duas áreas. Ilustrarei minhas idéias em relação às três tarefas centrais da administração: ${ }^{7}$ modelar, controlar e desenvolver organizações (e outros tipos de sistemas sociais).

\section{Modelagem da empresa para um fitness abrangente}

Modelar significa criar e manter uma instituição como uma entidade operacional, de modo que seja capaz de executar suas tarefas sem perder sua capacidade de controle e de desenvolvimento. $O$ caso seguinte ilustra bem esse ponto. Refere-se a uma entre muitas empresas em que trabalhei como consultor: uma companhia alemã que presta serviços de saúde e lazer. Esse exemplo é de par- ticular interesse já que é um dos poucos casos em que a evolução da empresa foi posteriormente examinada de forma sistemática, cinco anos após o início do projeto.

Nessa firma foi usado o Modelo do Sistema Viável (VSM - Viable System Model) de Stafford Beer como um guia para se diagnosticar e revisar a estrutura organizacional. ${ }^{8}$ Simplificando, estas foram as características desse empreendimento:

I. A empresa era constituída de várias unidades básicas (A, B, C e D, na Figura 1). Cada uma dessas unidades representava um negócio independente e operava em mercados claramente definidos, mesmo onde havia sobreposições: as unidades eram duas clínicas, um hotel e um balneário. Cada uma delas possuía a forma legal de uma companhia independente e uma administração própria (identificada por 1, na Figura 1).

Figura 1 - A estrutura da empresa representada em termos do VSM

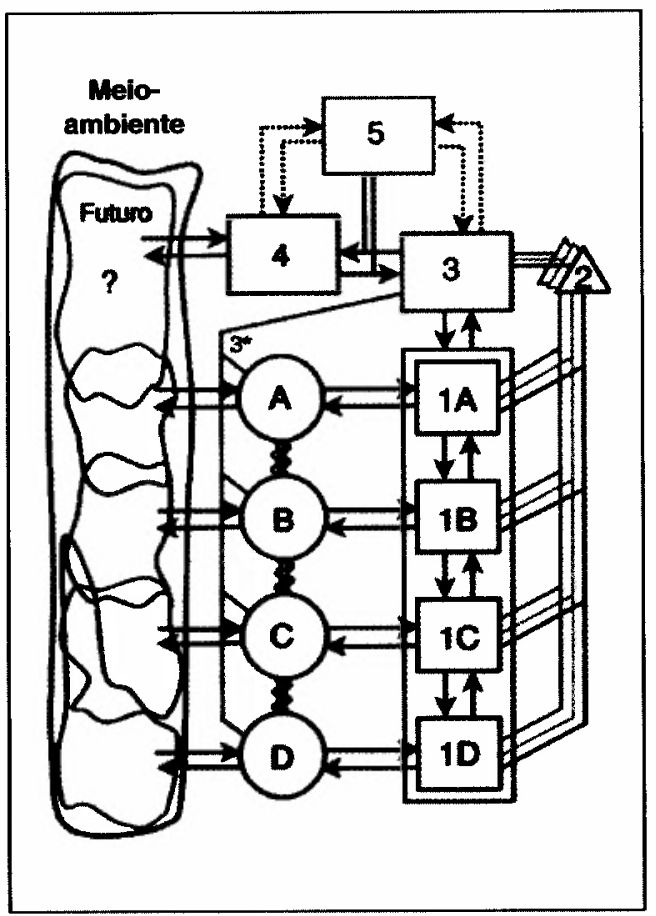

II. Anteriormente essas companhias haviam operado independentemente umas das outras. Pouco tempo antes de nossa intervenção, elas foram unidas em um holding. A razão dessa aliança era de cunho administrativo. Um holding management (identificado por 3, na Figura 1) tinha sido estabelecido para controlar (num sentido cibernético) a ad- 
ministração das companhias afiliadas, como indicado pelo eixo vertical no diagrama.

III. Um número de serviços centralizados - finanças e contabilidade, recursos humanos, tecnologia - já preenchia certas funções de coordenação. Além disso, outros mecanismos adicionais de coordenação e anti-oscilação também existiam (identificados por 2, na Figura 1), assim como processos de monitoramento (marcados como $3^{*}$ ), que não estariam indicados num organograma usual.

Até aqui, essa representação retrata a empresa do modo como funcionava antes de nossa intervenção. Operava de modo satisfatório, e os negócios diários eram realizados eficientemente. A empresa gozava de uma boa reputação, tanto junto aos clientes como na indústria em geral. A nova estrutura do holding daria margem a sinergias econômicas e organizacionais.

A despeito disso, a empresa carecia de uma orientação mais abrangente para com seu meio e dentro de um horizonte de longo prazo. $\mathrm{O}$ modo presente de fazer negócios seria ainda adequado no futuro? Muitas empresas que têm dado pouca atenção a tais questões se vêem, de repente, confrontadas com grandes dificuldades ou até mesmo com a falha total.

IV. Por essa razão foi estabelecida uma unidade com particular responsabilidade por uma abrangente orientação da empresa a longo prazo (unidade 4, na Figura 1). Uma equipe de 17 pessoas foi formada e reuniu-se em workshops, não somente para diagnosticar a situação à luz de uma perspectiva de longo prazo, mas também para redefinir as estratégias. De acordo com nossa proposta, essa equipe se constituiu em um círculo heterogêneo de administradores de linha, do presidente do conselho administrativo, passando pela diretoria, até os chefes de departamento e alguns suplentes. Dois motivos se destacavam:

a) assegurar que uma variedade de níveis organizacionais contribuiria ao projeto;

b) formar uma equipe multidisciplinar, incluindo profissionais de várias especialidades, administradores, técnicos e os médicos-chefes das clínicas.

Dessa maneira, foram criadas excelentes pré-condições para um trabalho realmente interdisciplinar e à altura da importância, da amplitude e da complexidade dos problemas em foco.
Todos os membros do conselho administrativo que participavam da equipe encarregada da estratégia eram ao mesmo tempo autoridades locais, entre elas o prefeito. Isso garantia a conexão adequada com o próximo nível estrutural, a autoridade local. Desse modo, foi incluído o contexto, o que é de grande importância na solução de problemas complexos.

V. Naturalmente, há, em empresas, freqüentes divergências de opinião entre as pessoas que se ocupam basicamente com atividades rotineiras e aquelas voltadas ao planejamento de longo prazo. A necessidade de integrar esses diferentes pontos de vista exige um sistema superordenado (Sistema 5, na Figura 1). Essa unidade equilibra, de um lado, (a) as perspectivas interna e externa e, por outro lado, (b) os imperativos de longo prazo e as possibilidades de curto prazo.

Para desempenhar essas tarefas, o Sistema 5 deve incorporar um modelo abrangente da realidade. Mais exatamente, um modelo que satisfaça o teorema de Conant \& Ashby: "Every good regulator of a system must be a model of that system".?

Dentro de uma empresa, há geralmente uma tendência a se atribuir essa função a uma certa pessoa ou a um certo grêmio. $\mathbf{O}$ que é uma simplificação indevida se tal unidade não dispor da variedade necessária. No nosso caso, o conselho administrativo, complementado pelo gerente-geral, assumiu a responsabilidade de formular e difundir os princípios a partir dos quais a companhia se fazia dirigir - isto é, a política empresarial. Em retrospectiva, esse modo se mostrou bastante eficaz.

Tanto sobre a estrutura da empresa em termos do VSM, com as funções:

- do management operativo;

- do management estratégico;

- do management normativo.

Um futuro sólido não pode ser construído simplesmente por meio de uma nova estrutura. Por essa razão se fez necessário definir uma identidade comum e uma arquitetura estratégica para a empresa e suas divisões. Conseqüentemente foi tomada uma série de decisões normativas e estratégicas. Os detalhes estão documentados em Schwaninger. ${ }^{10}$

A principal lição foi que a competênciachave da empresa era proporcionar saúde e não serviços de lazer. Portanto, decidiu-se valorizar o perfil da estância como um lugar
9. CONANT, R. C. ASHBY, W. R. Every Good Regulator of a System must be a Modal of that System, In: CONANT. Mochanisms. 205-214, 1981.

10. SCHWANINGER, M. Anwendung der integralen Unternehmungsentwicklung. Bern/Stuttgart: Haupt, 1988. 
de terapia e prevenção com tratamentos avançados para síndromes ortopédicas e respiratórias, assim como para a psoríase.

Também vale mencionar uma decisão à parte: decidiu-se não apenas qualificar os recursos humanos e tecnológicos, mas também investir maciçamente na proteção e no cultivo do meio ambiente, o que na época (anos 80) foi bastante avançado.

\section{Controle: um novo conceito de fitness organizacional}

$\mathrm{Na}$ seção anterior foram especificadas as condições estruturais para uma entidade operacional manter-se capaz de uma ação efetiva.

Mas como deve agir e funcionar uma empresa para que atinja seu fitness organizacional completo? Para esse fim, uma companhia deve ter capacidade para controlar a si mesma. A cibernética organizacional dá prioridade ao autocontrole e à auto-organização.

Um controle eficaz subentende um equilíbrio dinâmico, com nível satisfatório de desempenho, entre a companhia (ou uma unidade organizacional) e o seu meio ambiente. No entanto, quais variáveis definem um desempenho adequado? Esse não é apenas um problema de controle, mas também uma questão epistemológica fundamental: a questão do que podemos saber e de como usamos esses conhecimentos.

Modelos tradicionais de controle empresarial são baseados principalmente no objetivo de lucro. Tais modelos não satisfazem mais às exigências atuais. Sob a pressão evolutiva de uma complexidade crescente, avanços importantes têm sido alcançados com relação aos critérios de uma administração competente.

A essência desse progresso reside no reconhecimento de que um sistema deve controlar-se com a ajuda de variáveis de controle que podem ser contraditórias, já que pertencem a diferentes níveis lógicos: os níveis de administração operativa, estratégica e normativa (Figura 2).

As variáveis de controle essenciais ao nível operativo são a liquidez e o lucro. Desde a introdução da contabilidade dupla estamos cientes de que essas variáveis são dois objetos distintos tanto em relação ao conceito como à ação (anteriormente esse conhecimento não existia).

Os bons administradores sempre soube- ram que $\mathrm{o}$ alcance desses objetivos operacionais é ligado a condições a serem criadas com antecedência. Só recentemente tem surgido uma teoria prática que dá acesso a esses critérios de ordem lógica superior.

Da mesma maneira como o lucro predetermina a liquidez, os potenciais de valores (potenciais de sucesso) pré-controlam o lucro. O potencial de valores é definido como o conjunto de todos os pressupostos necessários à realização do lucro, que devem estar disponíveis quando se trata de materializá-lo. " $O$ potencial de valores deve ser controlado separadamente do lucro e da liquidez, com base em critérios independentes. A teoria da administração estratégica vem esclarecendo a natureza desses critérios. Por exemplo, como compreender os fatores críticos de sucesso de um dado negócio (tais como qualidade, participação de mercado, participação relativa de mercado, etc.) e como modifícar a posição competitiva, levando-se em conta o problema do cliente, as soluções para problemas, a substituição tecnológica e a value chain.

Com respeito à estratégia na empresa, uma metodologia para analisar e diagnosticar as competências-chave como base para a arquitetura estratégica se encontra disponível, ${ }^{12}$ tornando transparentes e sistematicamente manejáveis as variáveis essenciais em nível estratégico, de uma forma como anteriormente só era possível na esfera operativa.

Portanto, lucro não é uma variável de controle estratégico. Sua presença ou ausência é uma consequiência de boas ou más estratégias. Essa divergência da visão tradicional, que considerava lucro como o objetivo fundamental da empresa, tem sido expressa, em certo sentido, nas tentativas recentes de integrar a teoria financeira na estratégia da organização. ${ }^{13}$

Enquanto isso, o conhecimento das variáveis de referência no âmbito do management normativo também tem sido aprofundado. Os estudos respectivos são baseados principalmente na teoria de sistemas e na cibernética e novamente apresentam critérios independentes para a avaliação da viabilidade e do desenvolvimento das organizações.

Defino viabilidade como a manutenção de existência à parte, ou seja, de uma configuração distinta que torna um sistema distinguível como um conjunto. Ela pode ser 
avaliada com base em critérios estruturais, independentemente dos orientadores estratégicos e operacionais. A teoria estrutural mais avançada para julgar a viabilidade de uma organização é o Modelo do Sistema Viável (VSM - Viable System Model) de Stafford Beer. ${ }^{14}$

Quanto aos fatores soft da organização referidos pelo denominador comum de "cultura" -, têm-se desenvolvido modelos que, por enquanto, se prestam mais para fins descritivos e analíticos do que de design. ${ }^{15} \mathrm{Um}$ estudo recente dos professores Kotter e Heskett $^{16}$ da Universidade de Harvard distingue culturas adaptativas e não-adaptativas. Baseados em uma grande amostragem de empresas norte-americanas, os autores apontam um desempenho significativamente superior das primeiras em relação às últimas. Essas culturas adaptativas caracterizam-se por um esforço sustentado pelo pessoal (em todos os níveis da empresa) de proporcionar benefícios destacadas a todos os stakeholders principais, incluindo clientes e pessoal, e não só aos investidores.

Além disso, o paradigma emergente da organização aprendiz (learning organization) está delineando uma orientação renovadora tanto do ponto de vista estrutural como cultural.

De um ponto de vista sistêmico deve-se adotar a perspectiva de que uma organização aspira a uma viabilidade além da mera sobrevivência. $\mathbf{O}$ interesse focaliza-se mais no design de estruturas evolutivas, que podem até levar a uma nova identidade, do que em uma viabilidade no sentido limitado da palavra. Tal orientação estreita tem frequientemente levado à manutenção ou à auto-reprodução de sistemas cujo efeito ao conjunto maior foi negativo, ou seja, levou a uma autopoiese patológica.

Administradores avançados adotam cada vez mais uma abordagem sistêmica, na qual estendem seu sistema de referência, evitando uma perspectiva estreita: isso é corroborado pela crescente taxa de mudanças econômicas, jurídicas e estruturais, com o objetivo de criar novas entidades organizacionais viáveis. Desenvolvimento, no sentido do potencial crescente de um sistema para satisfazer tanto a suas demandas como às de outros, é um termo adequado para tal tipo de viabilidade além do "sobreviver". ${ }^{17}$

No âmbito do desenvolvimento, os indi- cadores tornam-se menos precisos. No entanto, a teoria de sistemas fornece idéias importantes para o diagnóstico da propensão de uma organização se desenvolver em função de propriedades (ou princípios filosóficos), tais como abertura e instabilidade, assim como a dinâmica inerente ao sistema. Critérios como autogoverno, amplificação catalítica e aprendizagem ajudam a julgar se um processo de mudança se qualifica como "desenvolvimento" ou não. ${ }^{18}$

Em suma, os indicadores no âmbito normativo são multifacetados; aqui, aspectos éticos, estéticos, sociais, políticos, culturais e ecológicos devem ser levados em consideração. Múltiplos constituintes e pontos de vista atribuem diferentes objetivos a um sistema social, o que conduz a uma ênfase em diferentes critérios de eficácia. Em um certo sentido, o conceito de controle que se aplica a esse nível normativo é incompatível com a compreensão derivada das ciências tradicionais. A instabilidade deixa de ser uma característica a ser eliminada completamente. Em um certo sentido e em certa medida, ela é um pressuposto necessário e válido para o desenvolvimento. ${ }^{19} \mathrm{Nem}$ por isso o (auto)controle deve contê-lo dentro de limites aceitáveis. Os tempos turbulentos das próximas décadas irão requerer cada vez mais um controle sobre o desenvolvimento, sobre a aprendizagem e sobre a transformação. A eficácia consistirá cada vez mais na capacidade de aprender, incluindo os modos de aprendizagem de ordem superior (aprendizagem de segunda ordem, metaaprendizagem), de desenvolver-se, reorientar-se e transformar-se.

Esforços sérios de se operacionalizar as variáveis soft e seu relacionamento com os índices de desempenho hard vêm sendo realizados. Citaremos, aqui, dois exemplos. Primeiro, estudos empíricos baseados em mais de 3.000 unidades de negócios realizados por PIMS indicam que as variáveis estratégicas geram $70 \%$ da variação do $\mathrm{ROI}$ - return on investment -, enquanto somente $30 \%$ dessa variação é explicada pelas variáveis que representam as decisões operacionais $\mathrm{e}$ as habilidades táticas. ${ }^{20}$ Segundo, um estudo de uma amostragem de empresas Fortune 1000 leva à conclusão de que os fatores organizacionais sobre as quotas de lucro são duas vezes mais influentes que os fatores econômi$\cos ^{21}$
14. Também há outras tentativas nesse campo, por exemplo, ver MINTZBERG, $H$. The effective organization: forces and forms. Sloan Management Review, p.5467, Winter, 1991.

15. DEAL, T. E., KENNEDY, A. A. Corporate cultures. the rites and rituals of corporate life. Reading. Massachusetts: Addison-Wesley, 1982

16. ACKOFF, R. L. The democratic corporation. New York/0xford: Oxford University Press, 1994; KOTTER, J., HESKETT, J. Corporate culture and performance. New York: Free Press, 1992.

17. SCHWANINGER, M. A concept of organizational fitness. In: ESPEJO, R. SCHWANINGER, M. Organisational Fitness, p.39-66, 1993.

18. ETZIONEI, A. The active society. a theory of societal and political processes. London/New York: Collier/MacMillan, s.d.; JANTSCH, E., WADDINGTON, C. H. (eds.) Evolution and consciousness. human systems in transition. Reading. Massachusetts: Addison-Wesley, 1976.

19. PRIOGOGINE, J. The philosophy of instability. Futures, p. 396-400, 1989.

20. BUZZELL, R. D., GALE, B. T. The PIMS Principles. New YorkLondon: Free Press/ Collier, 1987.

21. HANSEN, G. S., WERNERFELT, B. Determination of firm performance: the relative importance of economic and organizational factors. Strategic Management Journal, v.10, p.399-411, 1989. 
Nota-se que tanto essas variáveis de controle quanto os indicadores pertinentes não podem ser comparados em todos os aspectos, já que pertencem a três níveis lógicos diferentes (a plena consistência só pode ser alcançada dentro de cada um desses níveis lógicos). As variáveis reguladas em um nível representam os pré-controles para o nível diretamente abaixo.

A Figura 2 demonstra que os três níveis não são de maneira alguma separados uns dos outros. Ao contrário, cada nível inclui todos aqueles abaixo dele. Essa figura demonstra que os horizontes temporais crescem de baixo para cima. Ao mesmo tempo, tanto o horizonte dos conteúdos quanto a complexidade se expandem. As flechas pontilhadas indicam que certos princípios relevantes na administração normativa (éticos e estéticos) são essencialmente atemporais (timeless).

O diagrama mostra também que a problemática nos níveis superiores não é independente daquela dos níveis inferiores. Uma companhia só pode sobreviver se estiver de posse de potenciais e se esses forem materializados, isto é, convertidos em benefícios concretos. $O$ equilíbrio entre os sacrifícios decorrentes da formação de value potential e a colheita de seus frutos constituem outro pressuposto necessário para a viabilidade garantida pelo gerenciamento em nível normativo.

Nos três níveis lógicos de administração aplicam-se critérios diferentes de fitness organizacional ou, de modo abrangente, de efetividade sistêmica:

1. no nível operativo é o critério da eficiência econômica, principalmente em termos de lucratividade;

2. no nível estratégico é a eficácia tanto em termos de competição quanto de cooperação;

3. no nível normativo é a legitimidade, definida como o potencial de cumprir as reivindicações de todos os stakeholders relevantes.

A tarefa-chave de uma administração integral é satisfazer todas as três necessidades a longo prazo. Em outras palavras, o desafio consiste em garantir que a empresa seja bem sucedida em termos operacionais, inteligente em termos estratégicos e uma valiosa contribuidora para o conjunto maior, em termos normativos. Para cumprir essa delicada tarefa, uma empresa necessita de um siste-

Flgura 2 - Objetlvos e varlávels de controle: três nívels lóglcos

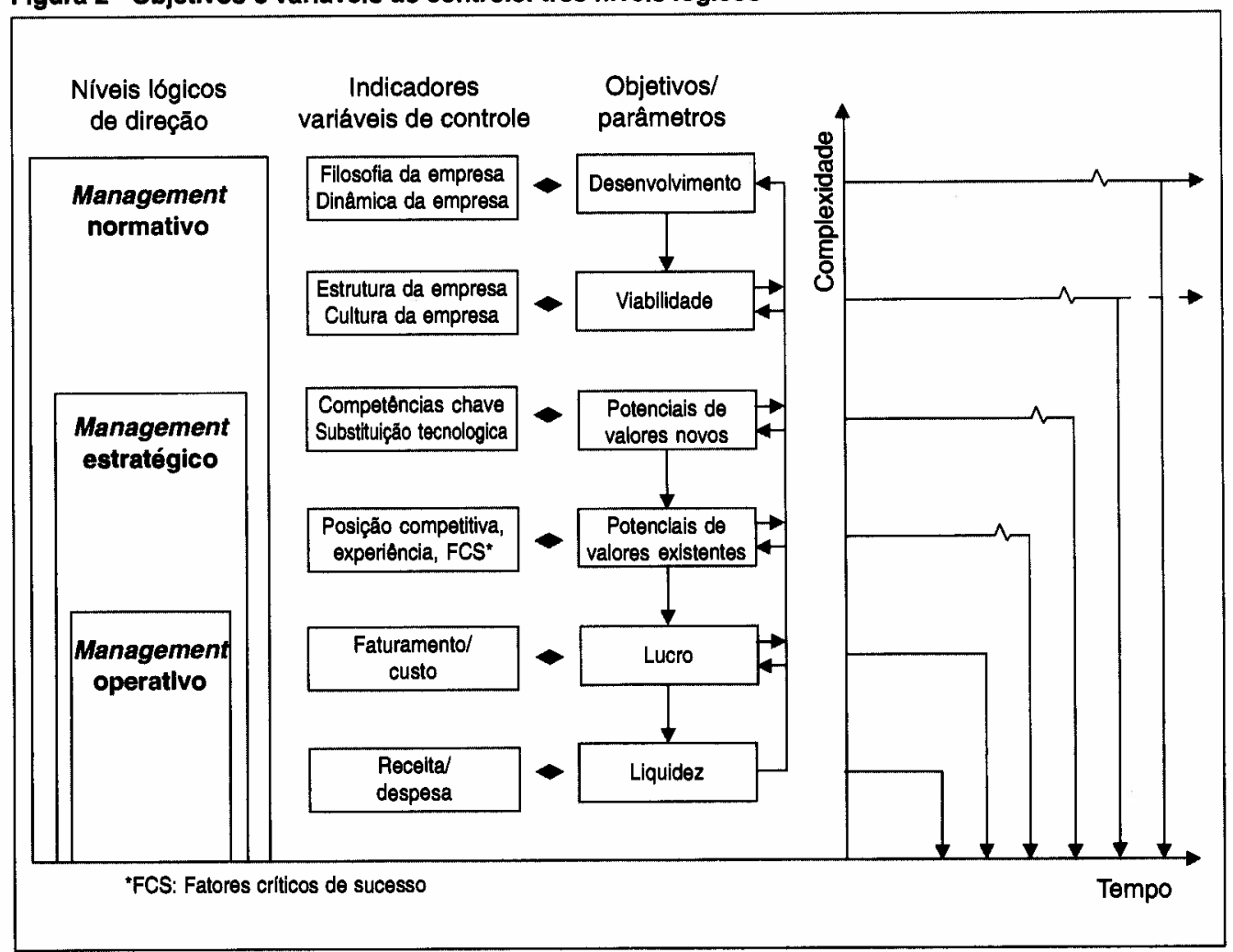


ma de controle consideravelmente mais complexo que os sistemas de controle de feedback tradicionalmente usados.

A hierarquia de variáveis de controle aqui delineada resulta em uma estrutura de controle de múltiplos níveis, condensada na Figura 3. A mesma esclarece que um mesmo sistema de negócios não pode ser pré-controlado com as mesmas variáveis com as quais está sendo controlado. Se, nessa estrutura, o controle se efetiva a partir do lucro (mediante as variáveis de controle pertinentes: faturamento e custo), então esse lucro não pode ser pré-controlado mediante as variáveis tradicionais de contabilidade. Assim, outras variáveis serão requeridas (o que é representado pelas linhas que ligam um ciclo com aquele anterior). Por essa razão o lucro não é um objetivo estratégico.

Retornando ao estudo de caso, o gerenciamento integral da empresa em questão significa que ela foi conduzida na base de variáveis de controle de todos os três níveis lógicos expostos.

O projeto conjunto de planejamento, descrito anteriormente, iniciou um importante processo para aquela empresa. O controle orçamentário, antes exclusivamente orientado pelo lucro, foi complementado usando-se critérios superiores: potenciais de sucesso, viabilidade e desenvolvimento. Em um meio ambiente em transformação isso deveria ter resultado em um verdadeiro processo de desenvolvimento.

\section{Desenvolvimento: fitness organizaclonal em ação}

Manifestações sistêmicas surpreendentes podem ocorrer em organizações sociais cujos potenciais se realizam. Do ponto de vista da cibernética, os processos de desenvolvimento não são aleatórios. São processos que obedecem a uma lógica evolutiva. Como tais, podem até um certo ponto ser influenciados no sentido de uma evolução planejada. Nesse processo, a amplificação catalítica das forças dinâmicas do sistema desempenha um papel importante.

Qual foi o resultado do esforço de iniciar e perseguir tal processo de desenvolvimento

Figura 3 - Management Integral como clclo multinlvelado

(dlagrama simpliflcado para um nível de recursão y)

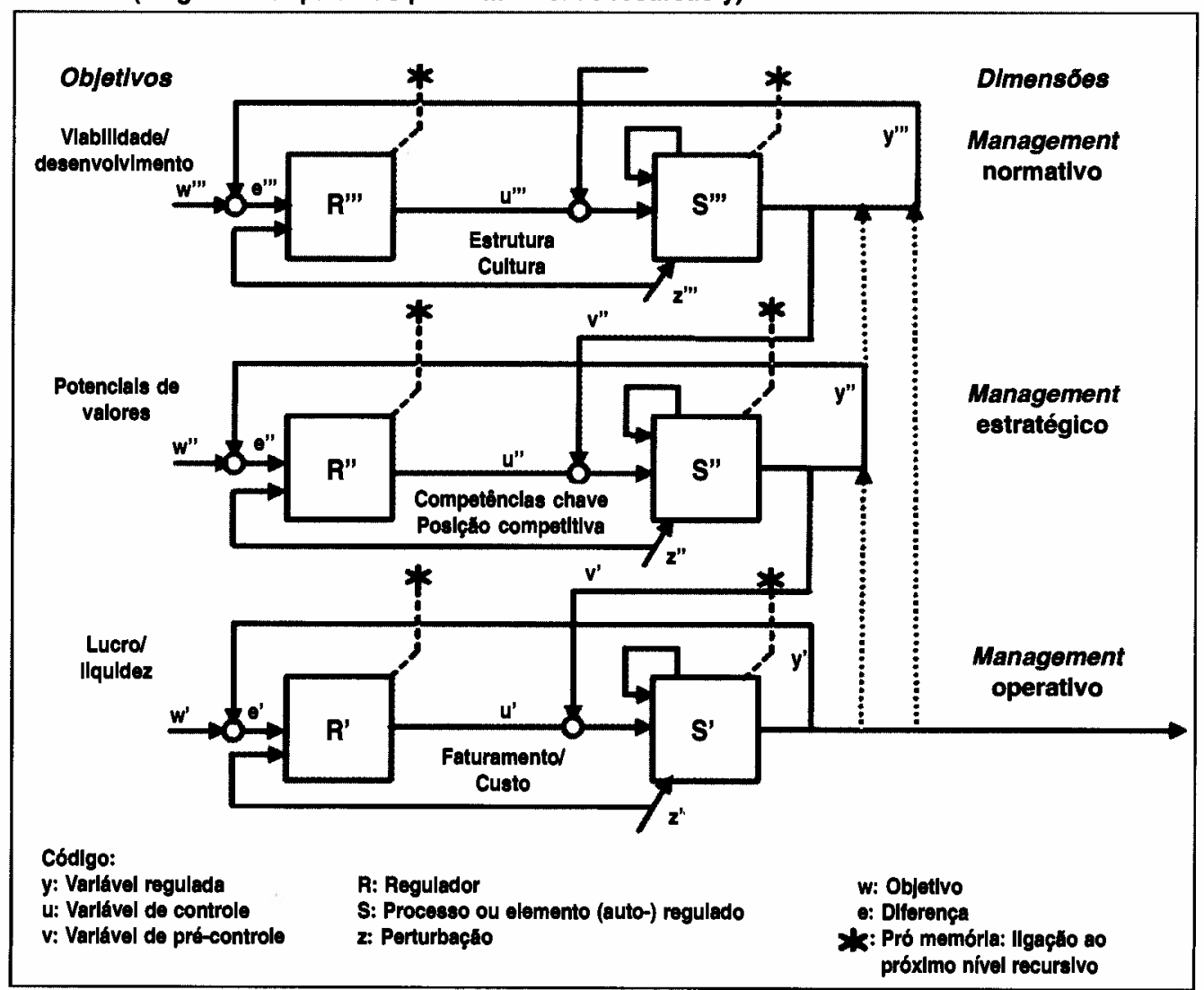


no caso descrito? Esse caso é valioso pelo fato de ser, dentre muitos outros projetos do tipo, o primeiro cujos efeitos foram examinados sistematicamente após um longo intervalo. Examinando como a empresa se apresenta cinco anos após a conclusão do projeto, pode-se ver que a mesma se submeteu a mudanças consideráveis. Entre outras coisas integrou duas companhias novas e efetuou reestruturações em nível organizacional e tecnológico, em ambos os casos com sucesso.

Este não é o momento de se analisar a evolução comercial em detalhe. O que interessa, porém, é um padrão de comportamento, observado em muitos outros casos. A Figura 5 mostra a evolução do volume de negócios a preços correntes, bem como a evolução da utilização da capacidade. Em resumo, ambas as quantidades cresceram entre o $4^{2}$ e o $9^{0}$ ano. O gráfico mostra, porém, um ponto de declínio: no caso, a crise da indústria entre os anos 5 e 6, levando a uma queda nas vendas, já pré-programada no estágio do planejamento (fim do ano 3 e início do ano 4), sendo, portanto, antecipada. Em comparação com a maioria das outras companhias do setor, essa empresa superou relativamente bem a crise.

Note-se que, nos anos 4 a 6 , a companhia continuou investindo maciçamente, apesar da queda drástica no faturamento (Figura 5). Apesar de prejuízos operacionais temporários, o investimento nos potenciais de valores continuou. Valorizaram-se os recursos técnicos das clínicas e embelezou-se a aparência da estância (mais árvores, flores, pedras naturais, menos concreto e asfalto). Foi, inclusive, a fase em que a empresa realizou os maiores investimentos apesar de passar por um de seus piores períodos do ponto de vista operativo.

Os frutos desse esforço tremendo são visíveis: a companhia está prosperando e tem influenciado positivamente a comunidade local e o meio ambiente, e os clientes estão satisfeitos.

Resumindo, uma lição essencial foi tirada daquele caso: a administração não foi desviada da rota pela recessão, não reagiu com pânico, como pode ser freqüentemente observado. Aquela perseverança somente trou$x e$ frutos porque era dirigida a fins maiores. Sem os princípios e a estratégia, as forças disponíveis teriam provavelmente sido usadas de forma vacilante. A dissipação da energia teria sido o resultado final. Em termos cibernéticos a empresa foi, de fato, dirigida na base de um sistema de orientadores de múltiplos níveis lógicos.

Mediante um follow-up rigoroso, foi identificado um efeito significativo de aprendizagem tanto da empresa como das pessoas envolvidas no projeto. O levantamento extensivo levou a uma conclusão clara: o processo

Figura 4 - Evoluçāo dos negócios (llustração do estudo de caso)

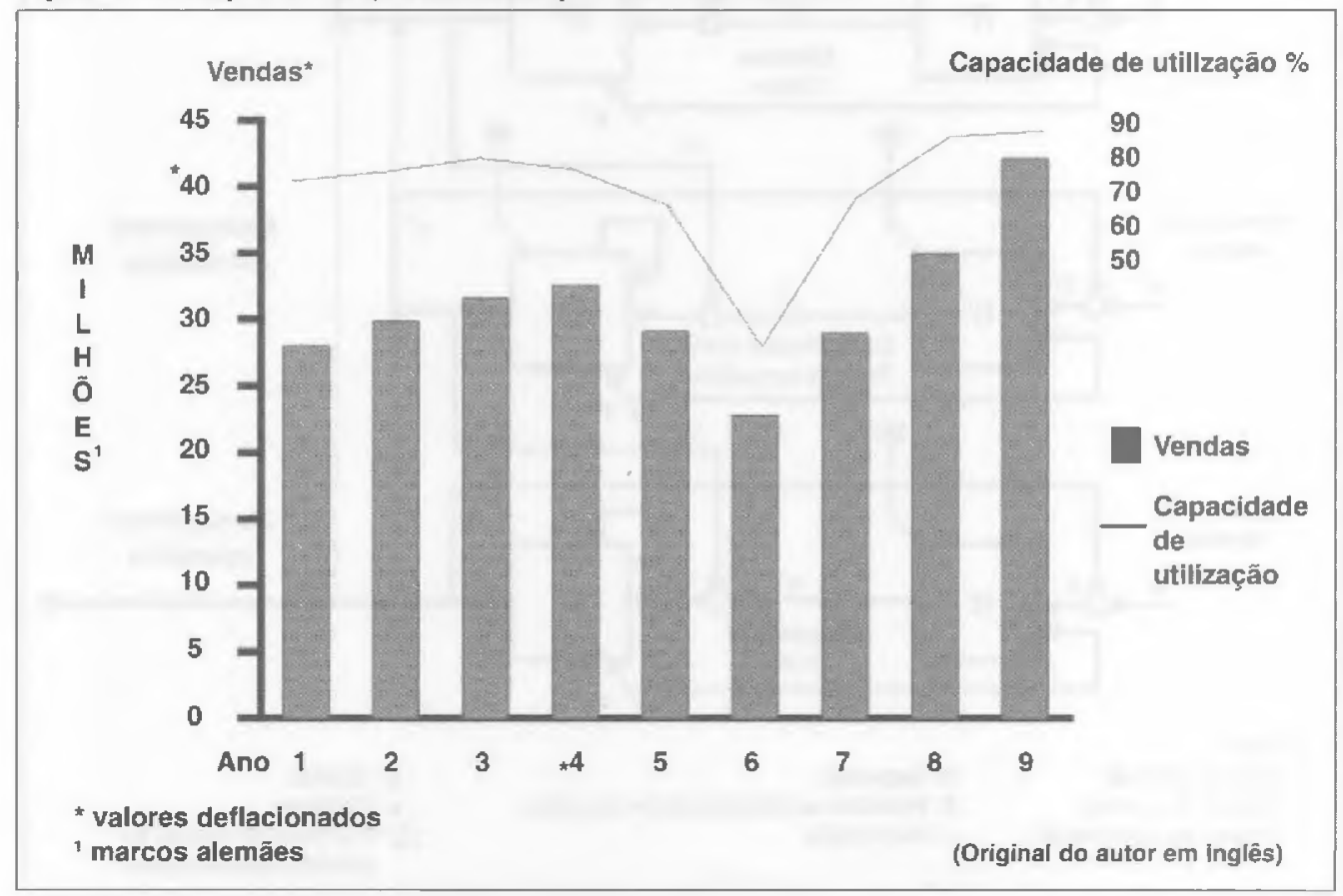


de planejamento tinha reforçado fortemente a inteligência da organização, sua abertura, aprendizagem e adaptabilidade. Esse caso não é uma exceção. Estudos sobre outras aplicações da mesma metodologia comprovam os resultados apresentados aqui. $\mathrm{O}$ ponto em questão é que os gerentes daquela empresa renunciaram a métodos de controle convencionais e unidimensionais, orientando suas ações por um conceito abrangente de fitness organizacional.

\section{CONCLUSÃO}

Os enfoques da administração de empresas com bases meramente econômicas carecem de uma teoria capaz de suportar o design e o controle de organizações de uma forma compreensiva, ou seja, voltada para a viabilidade e o desenvolvimento das mesmas.

A ciência da cibernética fornece um modo diferente de se focalizar as organizações, do qual se pode derivar uma concepção integral de administração. Tal enfoque implica uma compreensão complexa do fitness organizacional abrangendo vários níveis lógicos. Cada um desses níveis deve ser abordado com uma linguagem distinta, mas todos eles devem ser levados em considera' ção simultaneamente. Esse não é um processo mecanicista de controle, mas sim de autoreferência e de auto-organização.

Essa concep̧̧ão resulta em mais do que uma mera enumeração de critérios de eficá- cia. Ela fornece um conceito abrangente de fitness organizacional. Juntamente com o VSM (Modelo do Sistemas Viável), permite um design e um (auto)controle holístico de sistemas sociotécnicos visando à viabilidade e ao desenvolvimento:

1. Habilita organizações a se estruturarem e se reestruturarem como entidades capazes de ações conscientes e efetivas.

2. Ajuda-as a se controlarem de maneira que não sejam apenas bem sucedidas a curto prazo, mas também a se comportarem de forma inteligente e de maneira valiosa a longo prazo, inclusive em relação aos níveis sistêmicos superiores de que fazem parte.

3. Fornece uma moldura conceitual para a compreensão de reestruturações e aprendizagem como processos organizacionais que podem ser apoiados de modo consequiente. Como o exemplo demonstra, a concepção cibernética aqui proposta abre o caminho para um fitness em um sentido extenso. Entretanto, qualquer boa aplicação é alimentada pela consciência daqueles que a realizam. Ainda há um longo caminho a se percorrer e outros conhecimentos serão necessários para que essas idéias cibernéticas sejam postas em prática. Tais esforços valem a pena porque ajudam a desenvolver novas faculdades nas organizações: não só de se adaptarem a um meio ambiente em constante transformação, mas também de influenciálo de forma criativa em um processo de evolução conjunta.

Figura 5 - Investimento acumulado (ilustraçāo do estudo de caso)

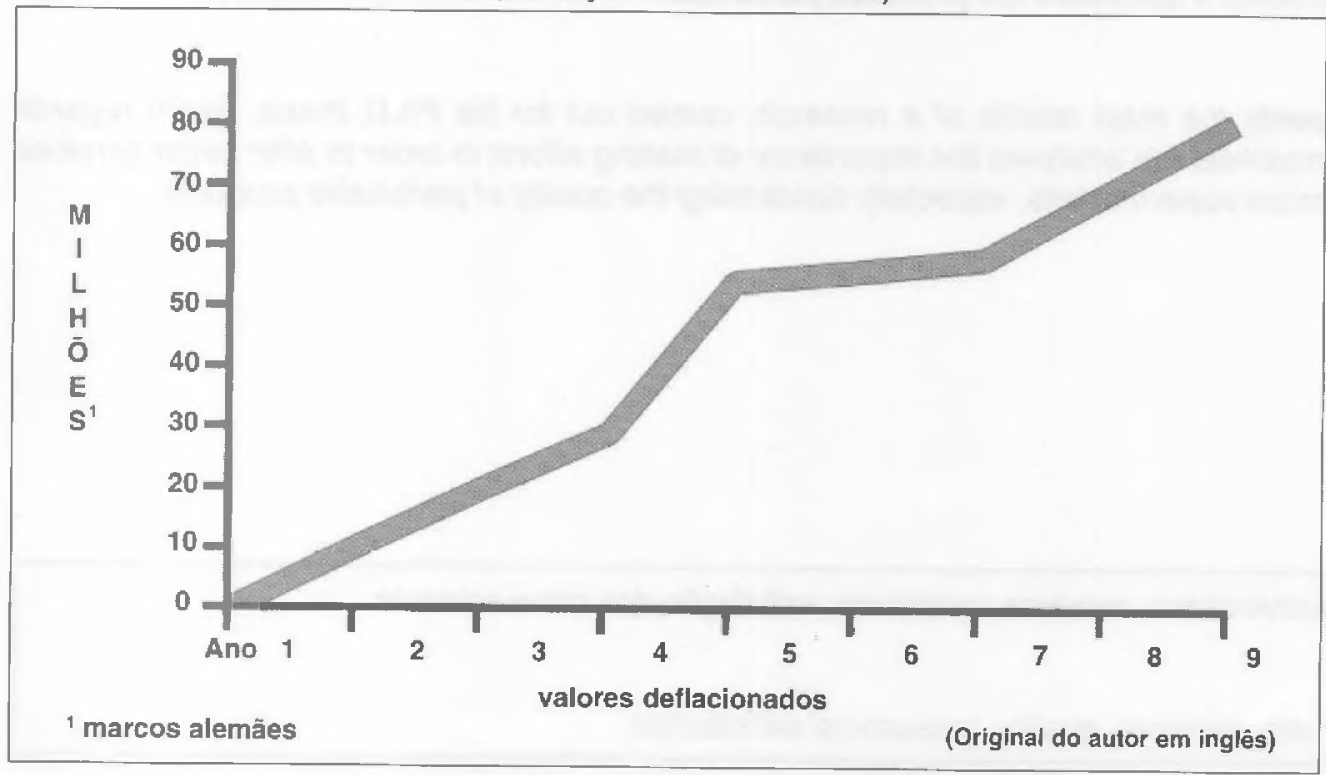

RAE • v. $38 \cdot$ ก. $3 \cdot$ Jul./Set. 1998 